\title{
Communication of Visual Anthropological Information: A Comparison between Visual and Written Anthropology
}

\author{
GAO Hui', HAO Yue-jun² \\ ${ }^{1}$ Department of International Cooperation, Kunming Metallurgy College, Kunming 650033, China; \\ ${ }^{2}$ Yunnan TV Station, Kunming 650031, China \\ a407127864@qq.com, b965299580@qq.com
}

Keywords: visual anthropological information; communication; visual anthropology; written anthropology; comparison

\begin{abstract}
These days, visual anthropology has been developed rapidly in China. A "film-based" expression of the anthropological films in academic standards is one of the theoretical and methodological issues to be solved in the development of visual anthropology in China. In terms of communication of anthropological information, anthropological film has a different emphasis with written anthropology. Through a comparison of the two kinds of transmission methods, the paper discusses the unique audio-visual expression language and the way of information communication of anthropological film and analyzes the trend of development and the background of the transmission mode of anthropological film information, aiming at realizing an overall connection of Chinese anthropological film method with that of the world.
\end{abstract}

\section{Introduction}

Nowadays, both anthropological film representation and written expression have undoubtedly become an effective way of anthropological observation, thinking and communication. The filming process in fieldwork is thought as a process (as same as using notebooks) of recognition, description and information communication of culture. However, visual and written anthropology are quite different in information communication. To match an anthropological paper with corresponding pictures, or events with only narrations is not a proper method for anthropological films. Anthropological film has its unique method, process and value, which is distinguished from printing and other media. Film record and narrative function is a kind of audio-visual record, expression and transmission of field observation rather than a conceptual expression of the media in anthropological studies. Researches on anthropological film's own information communication methods, that is , to solve and achieve a "film-oriented" representation of anthropological films in the academic norms instead of a process expression of recognition and description of cultures have been a trend for the development of visual anthropology in China.

\section{Images are the basic elements in communication of visual anthropological information.}

Every source of information in the film - the picture, is specific and concrete. Anthropological information of films is transferred in images, which is different from writing. Concreteness of the images constitutes the most basic elements in anthropological films, differentiating from that of anthropological writing. This characteristic (concreteness of images) in the information transmission of anthropological films shows mainly in the following levels:

The process of visual anthropology research and representation is to record a period of an object's behavior (events) in space and reflect the object's movement and development in some process, thereby, to record the external and spacial form of film subjects in some period of space, and then recur the visual information of the cultural characteristics of an event. This concreteness of image, being a single visual image, has nothing to do with the sense of smell and touch. It deprives the audience of the sense of temperature or season or flavor. Though the pictorial images may offer a semblance of reality, they are not reality. This is consistent with words. 
The specific means of visual anthropology determines its thinking mode to be mainly image thinking or provide mainly image information. The premise of the thinking is the perceived objective images, which depends on the direct effect the object perceived from the subject. There is nothing the camera can do once this effect disappears into a memory representation, that is, the thinking process of visual anthropological film is accomplished by reproducing an existing image and its thinking can only be carried on around this image.

Written anthropology can form a corresponding new image through a connection in the mind based on related text narration or drawings. New image and notion can be reconstructed through methods of abstraction, extraction, concentration, deduction and so on to memory representation, just according to library materials or second-hand fieldwork materials. Such as Lewis H. Morgan deduced and reconstructed the five forms of the history and development of human marriage and family on the basis of his research on the kinship system of Iroquois. This research method based on logical thinking can create a rational new image, but anthropological film cannot achieve an objective transformation of these rational "images", that is say, it can not create a materialized "reality" through the camera. In written anthropology, for example, a researcher can reconstruct and describe a disappeared (or even not existed) way of love in primitive society with some existing epic songs or other oral or written materials of a certain ethnic group, and then make a description and a rational analysis beyond the realistic representation ${ }^{[1]}$. Such " reconstruction" beyond reality is hard to do in the expression of film, as film and writing are different in dealing with time and other parameters, and in expressing human experiences. Film depicts what is happening through the visibility of images, while writing can fully describe the rational ethnographicness across time and space without the objects and reality, thus going beyond fieldwork and turning knowledge into consciousness.

In other words, the result of written anthropology can be independent of the actual image, while anthropological film must be dependent on reality. Therefore, anthropological film is suitable for describing "what is going on", that is, to record, describe the ongoing events and construct the image and scene through concretization and occurrence of events (memories, behaviors, experiences, etc.) ; and written expression is classified in a broader space, reconstructing the reality of the image and the scene through "thick description" ${ }^{[2]}$ and a image description of the reality.

3. The image characteristic of visual anthropology determines the multidimensional nature of the semantics of visual anthropology. Visual image is a global language. As far as its picture representation concerned, it does not have an invariant code. For example, the same dance movement may not be the same in religious rituals and in festival celebrations. Visual information is transmitted through the media. Researchers with different cultural background may encode the same information differently so that different conclusion may be made from the same visual image. The ethnological knowledge one single picture conveys is limited, and because of this, the anthropological film shows its tremendous analytical and thinking features.

4. The image characteristic of anthropological film determines its way of working on site and therefore the dependence of the film-maker on the shooting site. Film-makers must rely on the specific audio-visual language of the object to convey anthropological information, and this transmission can only be achieved in the process of recording. What I want to say is that, anthropological film never leaves the reality space, and it makes sense just when human behavior or social structure is displayed in its specific reality space, as its information source cannot be replaced or acted, and some visual scenes or objects cannot be filmed afterwards (such as some rituals). Visual elements of the film, including character, scene, line, color, light effect and other physical image elements, are parts of the existence of the object, which can never be separated from the material carrier of visual images. What the film can provide is a reproduction of human activities or behaviors. Scenes of the past cannot be refilmed. Therefore, the anthropological film's dependence on reality makes it difficult to leave the anthropological field and describe the history and the future directly with pictures.

Written anthropology can get new information through memories of the objects and reference and materials of previous investigations. The information sources and research media of written 
expression can be separated from the prototype of the objects, and exist in the memory system of thinking independently, which is no need to have direct and strict correspondence with the observed objects. The film involves far more concrete than abstract objects, so the visual text is not generally considered to be rigorously or rationally. However, both filming and writing "have to cope with the paradox that anthropological communication depends on presence and absence, or perhaps one might say, intimacy and distance."[3]

5. Due to its physical property, film takes on some potential information and irreversible "selectivity"which anthropological writing does not have. This potential information of anthropological film makes the film has a double character: it is not only a kind of record, but also a kind of "expression"language.

The real image information, as a real record of the reality, has been formed at the initial stage of the filming process, that is, many meanings and information in the final product have been included in the unedited footage. Therefore, the unedited anthropological film materials can be showed to the audience capable of decoding the images. However, in the process of anthropology writing, the readers cannot understand what it means until the words or the materials in the anthropologist's notebooks have been converted into specific meaning or information. On the other hand, the final anthropological product can only consist of materials made in the fieldwork, and no other new materials can be added in the follow-up editing. Therefore, the production of every new ethnographic work is the result of the fieldwork in person. Anthropological film cannot exist without the shooting sites. On the contrary, the final work of written anthropology may not include a paragraph or even a sentence from the record of fieldwork. The anthropologist can write articles without being there in person.

\section{The rich, subtle and diverse features of film language determines the multi-channel communication of anthropological information.}

The anthropological film's information is mainly transmitted by audio-visual language. It is a symbolic decoding system for the conversion of the realistic object, in which image and sound constitute a colorful and mysterious film symbol world. In the process of anthropological information communication, the "world" has developed a series of rules (code) that allow people to understand the ways in which symbols are combined or exchanged in order to achieve the purpose of accurate transmission of these information. The variety of code that the film has is far more than any other media.

The complexity, multiplicity and diversity of the code of anthropological film distinguishes it from written expression, which only depends on printed words to express and convey information. The code consists of five different components ${ }^{[4]}$ : moving visual images, phonetic sound, non-phonetic sound (include 'noise'), music, and writing or written text. Combination of these components decides the way of transferring information of a film. The "words" (including narration, subtitle) in a film belonging to one of the above five components is a part of code transmission by the object. Therefore, the information of the anthropological film text exists not only in images but also in words. ${ }^{[5]}$

Image, sound, word and other elements constitute the anthropological film information system, which provides an effective expression to the anthropologist to understand the information comprehensively. Other film techniques are also needed to achieve the visual expression of the anthropological film. For example, using "fade-out" and "fade-in" to show the passage of time, sound to keep the continuity of time and editing to get an unity of "event time", "narrative time" and "feeling time".

Film pictures allows us to fully experience the reality, and by watching the moving pictures, we can understand the objects and the process from the whole to the details. The written form arouses people's association by organizing and reorganizing the process from the details to the whole. In describing events, the anthropological film emphasizes strict chronological order and requires a relatively complete record of a process rather than fragmented sequences, as a single scene without context is difficult to convey an accurate information. When describing an object, film needs to 
carry a continuous expression from a number of points of sight to outline a basic profile and convey a main information, therefore, one camera is sometimes difficult to show multiple viewpoints at the same time, and the object and the action can only be described as a part of a relatively continuous segment. In other words, the production of film images is the result of a connection of various stages of the recorded movements. Film guides the audience through continuous sequences (not necessarily chronological) along a certain period of time of narration and illustration. A single decomposed sequence in an anthropological film may be of no significance. Some anthropological film genre need to be continuously tracing for many years. ${ }^{3}$ Literal expression, however, has a considerable flexibility and generality and is more free in the processing of time and space. Usually a few of words are capable of expressing a concept. In a film, time is limited, but it must be spared to allow an understanding of the information from a continuous linear watching, so, if a concept in the film is not clear and concise, it should be considered to delete, while in written anthropology, a note can be added to get an important transmission opportunity. This is why we say paper cannot replace film and vice versa.

\section{Differences in the way the reader accepts anthropological information}

Anthropological film attempts to explain the similarities and differences of one society to another, leading to one of the results of forming a very special cultural documentary. Today's anthropological film, as it should be, is no longer a private record of a society or a group, therefore, it is bound to involve the audience and will be inevitably watched and used by the community filmed. Anthropological film consequently must be more authentic, and should be made from various perspectives including from the audience's point of view. Written and visual expression of anthropology have a common feature in the discipline: they both belong to a reading behavior, the result of which is the expression of information and meaning, and the recombination of the information from the reader (audience).

Visual anthropology can use its unique linguistic advantage--image language to influence the rational standard. As it were, all knowledge and information contain "the senses (mainly 'governed' by 'brain'= 'nature'), the intelligible (mainly 'governed' by 'mind'='culture') and the relationship between them." [3]. Film attempts to create an understanding track so that the audience can experience the cultural connotation from the image expression. Written text, especially academic one, however, is characterized by its ration. It can be said that film tends to convey a sense of perception, while written text tries to get some explanation; film conveys the audience the process of forming and changing of facts and the inner feeling on people, while written text tends to give reality a sense of confrontation and analysis. To quote Wilton Martinez: “...while Iser sees the reading act as a complex of experimental phenomena and a series of cognitive acts leading to "gestalt-formation", film theory defines it as dialectic of symbolic-imaginary operations (eg. gazing, interpellation, suturing, subject-positioning)".[6]

The transmission of film information requires the participation of the audience. It is their response to the film that complete the communication of knowledge of anthropology. The audience is the participant of a meaning. They interact with film, using their own interpretation strategies and ideology to decode the information provided by the film, and in turn give it the meaning. From the anthropological point of view, the sensory structure of the audience need to be analyzed as a part of culture, so, in addition to an aesthetics of reception" ${ }^{[7]}$, an "reception of ethnography" is also needed in the study of anthropological film.

Anthropological film has the potential to deepen the understanding of cross culture and thus contributes to the formation of new consciousness. We can say that the "basis" of the authenticity of written anthropology depends mainly on the anthropologists according to the basic difference between the process of anthropological writing (data--textualization--text) and film-making (footage--editing--film). The anthropologist bears all the responsibility for the interpretation of books, articles or raw materials that have not been decoded. What is "real" has been filtered through his brain. In writing, every sentence in the article comes out of the mind of the anthropologist, therefore, the description may be exaggerated or even inauthentic. In The Golden Bough, Frazer's 
description of unfamiliar cultural practices is more magical beliefs than everyday rationality. Because this is writing, not film, it is impossible to describe the details of certain rituals (or life); while in anthropological film, "reality" also depends on photographer, sound engineer and editor though the final reorganization and interpretation lies in director (or anthropologist), and as mentioned above, the raw materials (including the explanation of the local people) have been largely decoded after the shooting. That is to say, though some parts of information provided by anthropological film are filtered by the photographer, the others are not processed by human brain at all and they are fully credible. Anthropological film is more objective and authentic compared with writing. Some researchers have questioned the objectivity and truth of the image because the object is optional, and even thought anthropological film could be false and could be a reconstruction, forgery and hypothesis of reality, as the establishment of similarity standard between visual description (pictures) and the object and event being depicted. As a matter of fact, books, languages are also capable of telling lies, and the probability is higher than films. ${ }^{4}$ Of course, problems are inevitable whether in anthropological writing or film.

Image and writing are two different ways of observing the world. Their difference is similar to that of "thin" and "thick" description (see Geertze above). Thin description is able to capture the appearance, behavior, but it is difficult to express the meaning. The external form, to some extent, is meaningless in culture. "Come" in one culture may mean "go" in another. As action and expression, they are the same, but as a social action, they are far from each other. Anthropological film is a continuous process. Such "come" or "go" is not a single action. It relates to the experience and the association of the audience through a complete description of the process.

The essence of the difference between the communication of anthropological film and writing lies in the form not the degree, as the two forms of expression are not in the same logic level. Therefore, they are not conflicting or complement each other but contact mutually on different expression channels. Writing contains a large number of visual description, and film includes the simulation of the methods of processes of anthropological fieldwork (observational film is the direct result of this simulation.)

In conclusion, anthropological information that visual anthropology wants to express and convey, namely, anthropological film record and communication of information in anthropology, has different emphases with writing, but they relate and complement each other. Visual anthropology, as a interdisciplinary subject, can not ignore the final carrier of the discipline--film, or overlook the film's visualized expression and the particularity and limitations of ways of this expression and description. Paying no attention to this and treating anthropological film as a simple repetition and duplication of written anthropology, the existence of the subject of visual anthropology which takes image as its way of expression and final achievement carrier will be meaningless.

Now in China, the development of visual anthropology has been paid more and more attention, and international academic exchange begins to develop. To understand the two different expression methods of film and writing and study the unique way of communication of anthropological film information has practical significance for Chinese anthropological film-making (whose related concept and method is obsolete and difficult to communicate with the international academic community) to break though and innovate to achieve an overall integration with the world.

\section{Notes}

1. Du Yuting (2009) gives a detailed and vivid description of the Jinuo Nationality as an example of the primitive love. But visual anthropological film can not complete the description unless it adopts a fictional method of filming. "Fictional method" is beyond the concerns of this paper.

2. Crawford shows the paradox of presence and absence and the anthropological process of "becoming" and "othering" with a diagram in his paper Film as discourse: the invention of anthropological realities. 
3. One example is Marshall's Ju/wasi of the Kalahari filmed in 1991, which can not be understood until watching other series followed up several years later.

4. I will not discuss it here as it is beyond the discussion of the differences between the two ways of expression.

\section{References}

Books and articles

[1] 杜玉亭. 和而不同的中国民族学探索：杜玉亭基诺族研究 [M]. 昆明：云南大学出版社, 2009.

[2] Geertz, Clifford. Thick Description:Toward an Interpretive Theory of Culture in The Interpretation of Cultures [M]. New York: Basic Books Inc. Publishers, 1973, 3-30.

[3] Crawford, Peter. I. Film as discourse: the invention of anthropological realities in Peter Ian Crawford and David Turton (eds.), Film as Ethnography [M]. Manchester and New York: University of Manchester Press, 1992, 68-70.

[4] Metz, Christian. Langage et Cinema, Paris. Donna Jean Umiker-Sebeok (trans.), Language and Cinema [M]. The Hague: Walter De Gruyter, 1974.

[5] 郝跃骏. 人类学电影学说及其流派分析[J]. 国外社会科学，1997（3）：16-21.

[6] Martinez, Wilton. Who constructs anthropological knowledge? Toward a theory of ethnographic film spectatorship in Peter Ian Crawford and David Turton (eds.) Film As Ethnography [M]. Manchester and New York: University of Manchester Press, 1992, 138-139.

[7] Jauss, Hans. R. Toward an Aesthetic of Reception [M]. Minneapolis: University of Minnesota Press, 1978.

Films

[1] Marshall, J. (1980), N!ai: The Story of a !Kung Woman, 1952-78, Colour, 59 mins.

[2] Marshall, J. (1962), Joking Relationship, Colour, 13 mins. 